\title{
Determination of cut-off and correlates of delay in treatment-seeking of febrile illness: a retrospective analysis
}

\author{
Himanshu K. Chaturvedi ${ }^{*}$, Ram C. Bajpai ${ }^{1,2}$ and Preeti Tiwari ${ }^{1}$
}

\begin{abstract}
Background: Early diagnosis and treatment of malaria symptoms reduces the risk of severe complication and malaria transmission. However, delay in malaria diagnosis and treatment is a major public health problem in India. The primary aim of the study was to determine cut-off for the delay in seeking treatment of fever, and the secondary aim was to identify the factors associated with delay in malaria-endemic areas of Assam, Northeast India.

Methods: The present study analysed data from two prior cross-sectional surveys (community- and hospital-based) that was conducted to study the health-seeking behaviour of people residing in high malaria-endemic areas of Assam, Northeast India. The hospital-based survey data were used to determine optimal cut-off for the delay in reporting, and further, used to identify the factors associated with delay using community-based data.

Results: Mean age of fever cases was similar in both community- and hospital-based surveys (23.1 years vs 24.2 years, $p=0.229$ ). Delay in reporting fever was significantly higher among hospital inpatients compared to community-based fever cases ( $3.6 \pm 2.1$ vs $4.0 \pm 2.6$ days; $p=0.006$ ). Delay of $>2$ days showed higher predictive ability (sensitivity: $96.4 \%$, and ROC area: $67.5 \%$ ) compared to other cut-off values ( $>3,>4$, and $>5$ days). Multivariable logistic regression analysis revealed that the adjusted odds ratio (aOR) of delay was significantly higher for people living in rural areas $(1.52,95 \% \mathrm{Cl}: 1.11-2.09)$, distance $(>5 \mathrm{~km})$ to health facility $(1.93,95 \% \mathrm{Cl}: 1.44-2.61)$, engaged in agriculture work (2.58,95\%Cl: 1.97-3.37), and interaction effect of adult male aged 20-40 years (1.71, 95\%Cl: 1.06-2.75).

Conclusion: The delay ( $>2$ days) in seeking treatment was likely to be twice among those who live in rural areas and travel $>5 \mathrm{~km}$ to assess health care facility. The findings of the study are useful in designing effective intervention programmes for early treatment of febrile illness to control malaria.
\end{abstract}

Keywords: Delay in reporting, Febrile illness, Malaria, Cut-off for the delay, Northeast India

\section{Background}

The World Health Organization (WHO) has accentuated that early diagnosis and prompt treatment for malaria should be occurred within $24-48 \mathrm{~h}$ of the onset of malaria symptoms to decrease the risk of severe

\footnotetext{
* Correspondence: chaturvedi_icmr@yahoo.com

'ICMR-National Institute of Medical Statistics, Indian Council of Medical Research, Ansari Nagar, New Delhi 110 029, India

Full list of author information is available at the end of the article
}

complications and onward transmission [1]. Good treatment-seeking behaviour and easy access to health services are important components imperative to its success. A prior study recommended that patients should seek medical treatment following the onset of fever, a common symptom of malaria [2]. It has been recognised that self-treatment may lead to more delay in seeking treatment $[2,3]$. Such delay may cause severe complications to patient within 3-7 days of onset of fever. The

(c) The Author(s). 2020 Open Access This article is licensed under a Creative Commons Attribution 4.0 International License, which permits use, sharing, adaptation, distribution and reproduction in any medium or format, as long as you give appropriate credit to the original author(s) and the source, provide a link to the Creative Commons licence, and indicate if changes were made. The images or other third party material in this article are included in the article's Creative Commons licence, unless indicated otherwise in a credit line to the material. If material is not included in the article's Creative Commons licence and your intended use is not permitted by statutory regulation or exceeds the permitted use, you will need to obtain permission directly from the copyright holder. To view a copy of this licence, visit http://creativecommons.org/licenses/by/4.0/ The Creative Commons Public Domain Dedication waiver (http://creativecommons.org/publicdomain/zero/1.0/) applies to the data made available in this article, unless otherwise stated in a credit line to the data. 
Plasmodium falciparum malaria causes a delay in cure, severe disease or death especially in multi-drug resistance areas [4].

Fever, the most common symptom of malaria, can be intermittent or continuous accompanied with other symptoms such as chills and rigours, headache, myalgia, arthralgia, anorexia, nausea and vomiting. The symptoms of malaria can be non-specific and mimic other diseases such as viral infections, and enteric fever etc. [5]. All fever cases are diagnosed as malaria either by rapid diagnostic kit (RDT) or microscopy, and choice of medicine depends upon whether the patient has $P$. vivax or $P$. falciparum malaria [6].

India has the highest number of malaria cases and related deaths in the Southeast Asia region [7, 8]. According to the National Vector Borne Disease Control Program (NVBDCP) annual report (2014-15), about 91\% of malaria cases and $99 \%$ of deaths due to malaria was reported from high disease burden states namely North-eastern (NE) States, Andhra Pradesh, Chhattisgarh, Gujarat, Jharkhand, Karnataka, Madhya Pradesh, Maharashtra, Odisha, Rajasthan and West Bengal [9]. High malaria transmission in Northeast India was due to the presence of various malaria parasites and vector species. The ecological condition, high rainfall and humid climate are favourable to growth and proliferation of the parasites and vectors in this region [9]. A previous study from Assam showed only $43 \%$ of febrile illness cases utilised government/private health services, and remaining used traditional and/or selfmedication [3]. The consequence of traditional and self-medication could result in misdiagnosis and incorrect choice of drugs, delay in diagnosis of malaria and increasing malaria transmission in the community $[2,3]$. The poor health care utilisation and orthodox health beliefs such as go-to priest, perform spiritual prayers, sacrifice a bird/animal are the key obstacles to early diagnosis of febrile illness [2, 3].

Malaria is curable with early diagnosis and treatment. Delay in treatment can lead to profound consequences including death $[1,4]$. An integrated approach of comprising both prevention and treatment with effective antimalarial agents is required to control Malaria. Prompt and effective treatment is also important for controlling the transmission of malaria [1]. Thus, to avoid such terrible effect of malaria it is important to catalyse the delay to treatment from the onset of fever and improve health-seeking behaviour of people [2].

Early treatment of febrile illness has been emphasised in the literature to control malaria, however, the knowledge about the correlates of the delay in seeking treatment is limited and without any defined cut-off for the delay. The optimum cut-off for the delay in the treatment of febrile illness is also required to work out especially for the malaria-endemic areas. In this study, we aimed to determine the optimum cut-off for the delay in seeking treatment of febrile illness and identify the factors associated with delay in the malaria-endemic areas of Assam, Northeast India.

\section{Methods}

\section{Study area}

Assam is bordered by Bhutan and Arunachal Pradesh to the north; Nagaland and Manipur to the east; Meghalaya, Tripura, Mizoram and Bangladesh to the south; and West Bengal to the west (Fig. 1). The state has total population 31.17 million with geographical area 78,438 $\mathrm{km}^{2}$ and thus the population density 398 persons per $\mathrm{km}^{2}$; and $85.9 \%$ population shared by the rural region of Assam (Census 2011). Production of tea, crude oil, natural gas, silk etc. are the major economic resources of the state. Assam, a flood-prone area, constitutes two major valleys namely Brahmaputra and Barak which intersperses hill ranges, difficult terrain and an evergreen rain forest covering nearly $40 \%$ of the geographical area. With pre-monsoon showers (March and April), the heavy rainfall of two meters or more recorded during monsoon from July to September. The relative humidity varying from 70 to $85 \%$ throughout the year makes the overall environment conducive for mosquito proliferation, survival, and longevity and favours active malaria transmission. Health services in the state were mainly provided by the government (district hospitals, community health centres $(\mathrm{CHCs})$, primary health centres (PHCs), sub-centres (SHCs)) and private service providers (private hospitals, tea-garden hospitals, other hospitals of industries). Health insurance schemes for the general public and cashless health insurance scheme by the government for poor people has been started, but its coverage and impact on public health is not yet known. A study on healthseeking behaviour of people was conducted in two districts of high malaria-endemic area of upper Assam, namely Tinsukia and Golaghat. Data were collected at the household level to assess the treatmentseeking behaviour of people and at the health facility level to know the prevalence of malaria among febrile patients.

\section{Study design}

We used data from two previously conducted surveys on health-seeking behaviour of febrile illness of people in Assam state of India. One survey was conducted among inpatients in some pre-selected hospitals, whereas the other survey was conducted at the household level in the same selected two districts during the same period. 


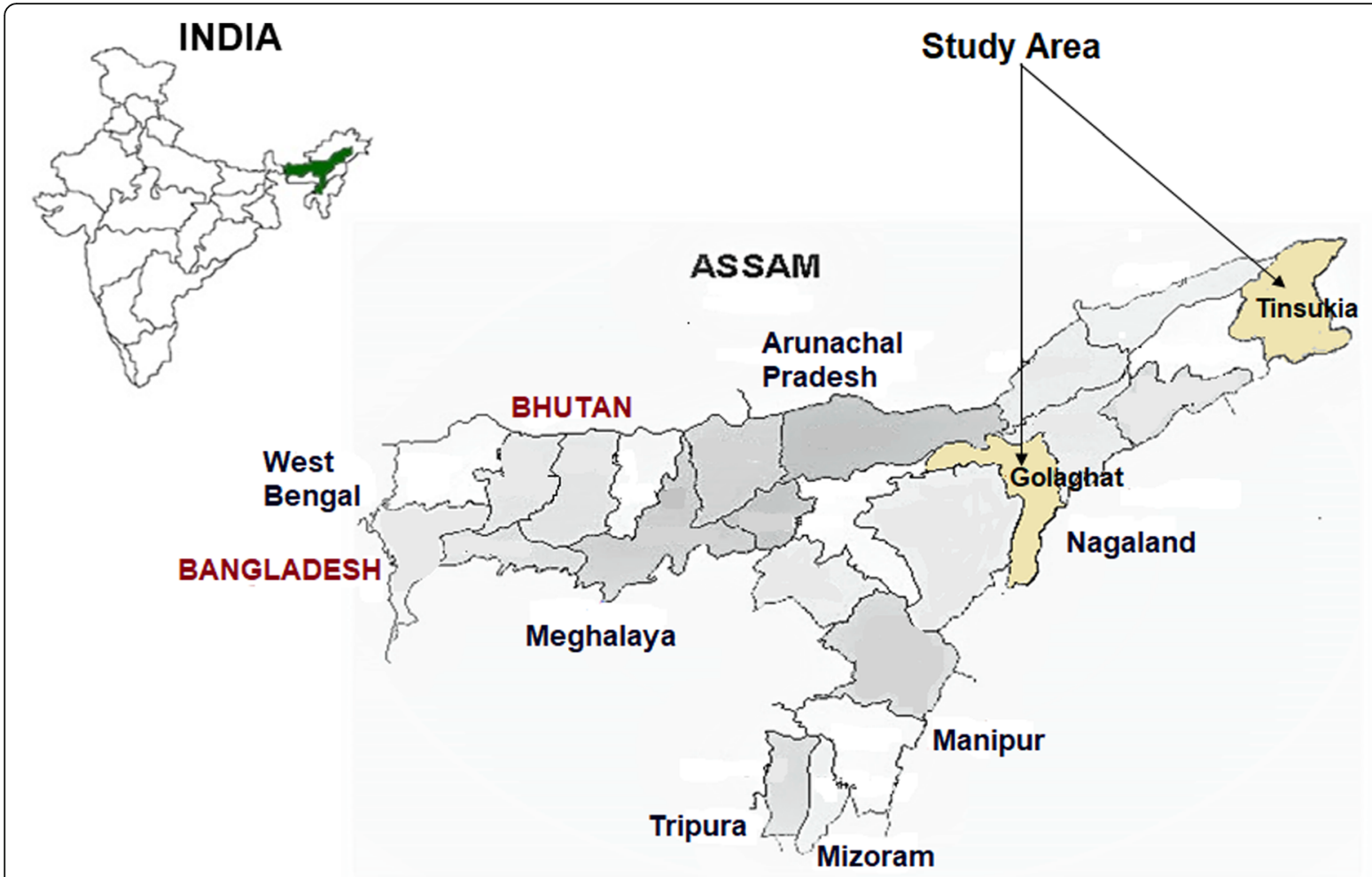

Fig. 1 The map shows the geographic location of Tinsukia and Golaghat districts of Assam selected as study area. Source: http://censusindia.gov.in/maps/State_Maps/StateMaps_links/assam.jpg

Hospital-based survey data were used to find the optimal cut-off for the delay in reporting to the hospital for seeking treatment and risk of malaria among them, whereas household survey data were used to apply the obtained cut-off to know the factors associated with delay. A brief description of hospital- and community-based surveys is presented below.

\section{Community-based survey}

Household survey was carried out in randomly selected 100 primary sampling units (PSUs) covering wards in urban and villages in rural areas of the selected study area. In each PSU's, a list of all households was prepared and those households who had reported a case of malaria or fever in last 3 months and described the symptom of disease before seeking treatment were recorded. A sample of 20 such households who received treatment of fever was selected randomly. If the list of such households was less than or equal to 20, all of them were included for the survey. The head of the selected households was interviewed to collect general information whereas specific information related to the treatment of fever was collected from the individual patient or mother of sick child in a pre-tested questionnaire [3].

\section{Hospital-based survey}

Survey was also conducted in six government hospitals (three in urban and three in rural), six private hospitals and four tea garden hospitals (i.e. community hospitals) to collect information from the inpatients reported for treatment of febrile illness. These hospitals were selected based on health facility services for the treatment of malaria and the availability of patients reported with fever. All the febrile patients who reported to the selected hospitals during the study period were assessed by the physician and those who were admitted and suspected of having malaria were included in the study. Patients admitted to the hospital with febrile illness, but who were not suspected of having malaria, were excluded. The patients included in the study were interviewed by trained Field Investigators for collection of general information related to health-seeking behaviour including delay in reporting for treatment, utilization of health services and diagnosis of fever using the pre-tested questionnaire [2]. 
Table 1 General profile of fever cases in the community and hospital surveys in the malaria-endemic areas of Assam, Northeast India

\begin{tabular}{|c|c|c|c|c|}
\hline \multirow[t]{2}{*}{ Background characteristics } & \multicolumn{2}{|l|}{ Type of survey } & \multirow[t]{2}{*}{$x^{2} / Z$ test } & \multirow[t]{2}{*}{$\overline{p \text {-value }}$} \\
\hline & Community & Hospital & & \\
\hline Total fever cases & 1989 & 350 & & \\
\hline \multicolumn{5}{|l|}{ District $(n, \%)$} \\
\hline Golaghat & $995(50.0)$ & $187(53.4)$ & 0.9 & 0.329 \\
\hline Tinsukia & $994(50.0)$ & $163(46.6)$ & & \\
\hline \multicolumn{5}{|l|}{ Age group (years) $(n, \%)$} \\
\hline$<20$ & $1080(54.3)$ & $147(42.0)$ & 33.2 & $<0.001$ \\
\hline $20-40$ & $525(26.4)$ & $145(41.1)$ & & \\
\hline$>40$ & $383(19.3)$ & $58(16.6)$ & & \\
\hline \multicolumn{5}{|l|}{ Gender ( $n, \%)$} \\
\hline Female & $1171(58.9)$ & $132(37.7)$ & 54 & $<0.001$ \\
\hline Male & $818(41.1)$ & $218(62.3)$ & & \\
\hline \multicolumn{5}{|l|}{ Religion $(n, \%)$} \\
\hline Hindu & $1841(92.6)$ & $316(90.3)$ & 2.1 & 0.143 \\
\hline Others & $148(7.4)$ & $34(9.7)$ & & \\
\hline \multicolumn{5}{|l|}{ Occupation ( $n, \%)$} \\
\hline Not-working & $528(26.5)$ & $127(36.3)$ & 52.4 & $<0.001$ \\
\hline Agriculture & $774(38.9)$ & $170(48.6)$ & & \\
\hline Non-agriculture & $687(34.5)$ & $53(15.1)$ & & \\
\hline \multicolumn{5}{|l|}{ Place of residence $(n, \%)$} \\
\hline Rural & $1750(88.0)$ & $113(32.3)$ & 569.6 & $<0.001$ \\
\hline Urban & $239(12.0)$ & $237(67.7)$ & & \\
\hline \multicolumn{5}{|l|}{ Health Services ( $n, \%)$} \\
\hline Government & $1303(65.5)$ & $198(56.6)$ & 106.1 & $<0.001$ \\
\hline Private & $686(34.5)$ & $152(43.4)$ & & \\
\hline \multicolumn{5}{|l|}{ Continuous data (mean \pm SD) } \\
\hline Age of fever cases (years) & $23.1 \pm 18.7$ & $24.2 \pm 15.2$ & 1.2 & 0.229 \\
\hline Monthly family income (INR) & $2534 \pm 1816$ & $3610 \pm 2029$ & 9.29 & $<0.001$ \\
\hline Distance to health centre (km) & $4.2 \pm 5.0$ & $17.0 \pm 20.1$ & 11.9 & $<0.001$ \\
\hline Delay in reporting (days) & $3.6 \pm 2.1$ & $4.0 \pm 2.6$ & 2.7 & 0.006 \\
\hline Duration of treatment (days) & $4.5 \pm 3.2$ & $4.3 \pm 3.8$ & 0.9 & 0.353 \\
\hline Expenditure on medicines (INR) & $118.1 \pm 248.6$ & $454.5 \pm 388.6$ & 15.7 & $<0.001$ \\
\hline
\end{tabular}

\section{Data analysis}

Data used for this study were extracted from household survey on health-seeking behaviour and hospital-based survey of febrile patients reported for treatment. Background characteristics such as age, sex, religion, place of residence, monthly family income, and distance to health care facility etc. were considered to assess any association with delay in seeking tratement $[2,3]$. Age was categorized into three groups as $<20,20-40$ and $>40$ years. Occupation of respondents was also categorized into working groups such as agriculture and non-agricultural work (self-employed and service), and not-working group (housewife and others). The family income of respondents was categorized as $<5000$ and $\geq 5000$ INR. The normality of the continuous variables is tested by Shapiro-Wilk and Shapiro-Francia test statistics before comparing the means by Mann-Whitney $U$ test or Student's t-test. The Spearman rank correlation was used to explore the correlation between delay in treatment of fever and duration of fever treatment. 
Table 2 Goodness-of-fit measures for various cut-offs for the delay in reporting among fever cases using hospital-based survey data $(N=350)$

\begin{tabular}{|c|c|c|c|c|}
\hline \multirow[t]{2}{*}{ Goodness-of-fit parameters } & \multicolumn{4}{|c|}{ Logistic models with various cut-offs for delay } \\
\hline & $>2$ days & $>3$ days & $>4$ days & $>5$ days \\
\hline \multicolumn{5}{|l|}{ Overall model fit } \\
\hline Log likelihood & -195.8208 & -230.0087 & -207.0900 & -171.8360 \\
\hline $\mathrm{AlC}$ & 417.6415 & 486.0173 & 440.1800 & 369.6721 \\
\hline $\mathrm{BIC}$ & 467.7946 & 536.1704 & 490.3331 & 419.8252 \\
\hline Hosmer-Lemeshow test p-value & 0.5965 & 0.5136 & 0.4436 & 0.2497 \\
\hline \multicolumn{5}{|l|}{ Model discrimination } \\
\hline $\mathrm{ROC}$ area & 0.6748 & 0.6474 & 0.6626 & 0.6430 \\
\hline Somers' D statistic & 0.3495 & 0.2947 & 0.3253 & 0.2860 \\
\hline \multicolumn{5}{|l|}{ Model classification } \\
\hline Sensitivity & 0.9639 & 0.6222 & 0.1339 & 0.0000 \\
\hline Specificity & 0.1485 & 0.6118 & 0.9370 & 100.00 \\
\hline Positive predictive value (PPV) & 0.7362 & 0.6292 & 0.5000 & 0.0000 \\
\hline Negative predictive value (NPV) & 0.6250 & 0.6047 & 0.6969 & 0.7914 \\
\hline Correctly classified & 0.7286 & 0.6171 & 0.6800 & 0.7914 \\
\hline \multicolumn{5}{|l|}{ Model calibration } \\
\hline Brier score & 0.1876 & 0.2327 & 0.2031 & 0.1585 \\
\hline CITL & $-2.63 \mathrm{E}-10$ & 4.90E-08 & 4.95E-08 & $-7.06 \mathrm{E}-08$ \\
\hline E/O ratio & 1 & 1 & 1 & 1 \\
\hline C-slope & $-1.79 \mathrm{E}-08$ & $-9.34 \mathrm{E}-10$ & $-4.49 \mathrm{E}-09$ & $1.26 \mathrm{E}-08$ \\
\hline
\end{tabular}

AIC Alike information criterion, BIC Bayesian information criterion, $R O C$ receiver operation characteristic, CITL calibration-in-the-large, E/O expected/observed, C-slope: calibration-slope

We hypothesised that hospital-based fever data were collected in more controlled conditions. Therefore, we used it to find optimal cut-off for the delay in reporting (days). Number of multivariable logistic regression models were fitted for the delay in reporting at each cutpoints i.e., $>2,>3,>4$ and $>5$ days respectively. Various goodness-of-fit measures were calculated for each fitted model and compared with each other to find the best fit for the fever data at a given cut-off value. Overall fit was assessed by log-likelihood, Akaike information criterion (AIC), Bayesian information criterion (BIC), and Hosmer-Lemeshow test. Model discrimination was assessed by area under the receiver operating characteristic (AUROC), and Somer's D statistics. Model classification was measured by sensitivity, specificity, positive predictive value (PPV), negative predictive value (NPV) and the overall ability for correct classification. Model calibration was assessed by Brier score, calibration-inthe-large coefficient (CITL), expected/observed ratio, calibration slop, and calibration plot. Our decision for optimal cut-off was based on goodness-of-fit performance in the majority of indices [10-12].

Further, we validated this cut-off in the communitybased fever data. We fitted univariable and multivariable logistic regression models to find factors associated with the delay in reporting. The odds ratios (ORs) were calculated and reported with corresponding 95\% confidence intervals (CIs). We also checked for possible interactions between delay in reporting, and predictor variables, and reported in the regression table if its $p$-value was found to be less than 0.1 (using more conservative criteria). The goodness-of-fit for the multivariable model was ascertained by overall fit, discrimination, calibration, and classification as previously described. We used Stata 14.2 (StataCorp, College Station, TX, US) statistical software for analysis of the data.

\section{Results}

The socio-demographic profile of fever cases including delay in reporting and duration of treatment are presented for the two surveys in Table 1. Significant differences in the pattern of distribution by age, gender, type of work related to occupation, place of residence and health services used for treatment was observed between two surveys of fever cases. The average age of fever cases was similar in both surveys (23.1 years in community and 24.2 years in hospital surveys; $p=0.229$ ). The average household/family income reported was significantly higher in the hospital survey (INR 3610) compare with household survey (INR 2534). The mean delay in 
Table 3 Correlates of delay (> 2 days) in treatment-seeking for febrile illness among the people (community-based survey) of malaria-endemic areas of Assam, Northeast India

\begin{tabular}{|c|c|c|c|c|}
\hline Characteristics & $\mathrm{N}$ & Delay (\%) & Unadjusted OR (95\% C.I.) & Adjusted OR (95\% C.I.) \\
\hline \multicolumn{5}{|l|}{ District } \\
\hline Golaghat & 995 & 61.2 & 1 & 1 \\
\hline Tinsukia & 994 & 70.4 & $1.51 f(1.25-1.82)$ & $2.13 f(1.73-2.68)$ \\
\hline \multicolumn{5}{|l|}{ Age group (year) } \\
\hline$<20$ & 1080 & 63.4 & 1 & 1 \\
\hline $20-40$ & 525 & 66.7 & $1.16(0.93-1.44)$ & $0.85(0.60-1.20)$ \\
\hline$>40$ & 383 & 71.5 & $1.45 f(1.13-1.87)$ & $1.15(0.75-1.75)$ \\
\hline \multicolumn{5}{|l|}{ Gender } \\
\hline Female & 1171 & 67.6 & $1.22 \mathrm{e}(1.01-1.47)$ & $0.85(0.65-1.11)$ \\
\hline Male & 818 & 63.2 & 1 & 1 \\
\hline \multicolumn{5}{|l|}{ Religion } \\
\hline Hindu & 1841 & 66.6 & 1.56e (1.11-2.19) & $1.99 f(1.36-2.92)$ \\
\hline Others & 148 & 56.1 & 1 & 1 \\
\hline \multicolumn{5}{|c|}{ Monthly family income (INR) } \\
\hline$<5000$ & 1772 & 67.2 & $1.68 f(1.27-2.24)$ & $1.18(0.86-1.62)$ \\
\hline$\geq 5000$ & 217 & 54.8 & 1 & 1 \\
\hline \multicolumn{5}{|l|}{ Type of work } \\
\hline Not working & 528 & 51.9 & 1 & 1 \\
\hline Agriculture & 774 & 79.6 & $3.61 f(2.83-4.61)$ & $2.58 f(1.97-3.37)$ \\
\hline Non-agriculture & 687 & 61.0 & $1.45 f(1.15-1.82)$ & $1.54 f(1.20-1.96)$ \\
\hline \multicolumn{5}{|l|}{ Place of residence } \\
\hline Rural & 1750 & 68.0 & $2.14 f(1.63-2.82)$ & 1.52e (1.11-2.09) \\
\hline Urban & 239 & 49.8 & 1 & 1 \\
\hline \multicolumn{5}{|c|}{ Distance to health centre $(\mathrm{km})$} \\
\hline$\leq 5$ & 1565 & 61.5 & 1 & 1 \\
\hline$>5$ & 424 & 81.6 & $2.77 f(2.13-3.62)$ & $1.93 f(1.44-2.61)$ \\
\hline \multicolumn{5}{|l|}{ Type of hospital } \\
\hline Government & 1303 & 72.6 & $2.36 f(1.94-2.86)$ & $2.41 f(1.92-3.03)$ \\
\hline Private & 686 & 52.9 & 1 & 1 \\
\hline \multicolumn{5}{|l|}{ Interaction terms } \\
\hline Age $20-40$ years*Males & & & & $1.71 \mathrm{e}(1.06-2.75)$ \\
\hline Total & 1989 & 65.8 & - & - \\
\hline
\end{tabular}

Note: $O R$ odds ratio, C.I. confidence interval, INR Indian rupees; $\mathrm{e}=p<0.05 ; \mathrm{f}=p<0.01$

reporting for treatment of fever was recorded significantly higher in-hospital survey (4 days in hospital and 3.6 days in community surveys; $p<0.01$ ), whereas average expenditure on medicines (Indian rupees 455 in hospital and 118 in community surveys; $p<0.001$ ) was three times more for fever patients reported to hospitals. Of the 350 cases reported with febrile illness, 97 (27.7\%) cases were diagnosed as malaria in the hospital survey. Distribution of delay in reporting for treatment and moderate positive correlation (Spearman's rho $=0.54$; $p<0.01$ ) was observed between the delay in reporting fever and duration of treatment (Supplementary Fig. S1 \& S2).

Table 2 presents the number of goodness-of-fit measures for each fitted model using the hospital-based survey. Overall delay $>2$ days cut-off showed better fit in the majority of model fitting parameters. Overall discrimination ability was highest to delay $>2$ days (ROC area $=0.6748$, and Somer's D statistic $=0.3495$ ) with compare to other cut-offs. Model classification parameters such as sensitivity, specificity, PPVs, NPVs, and overall classification also indicated good fit for delay $>2$ 

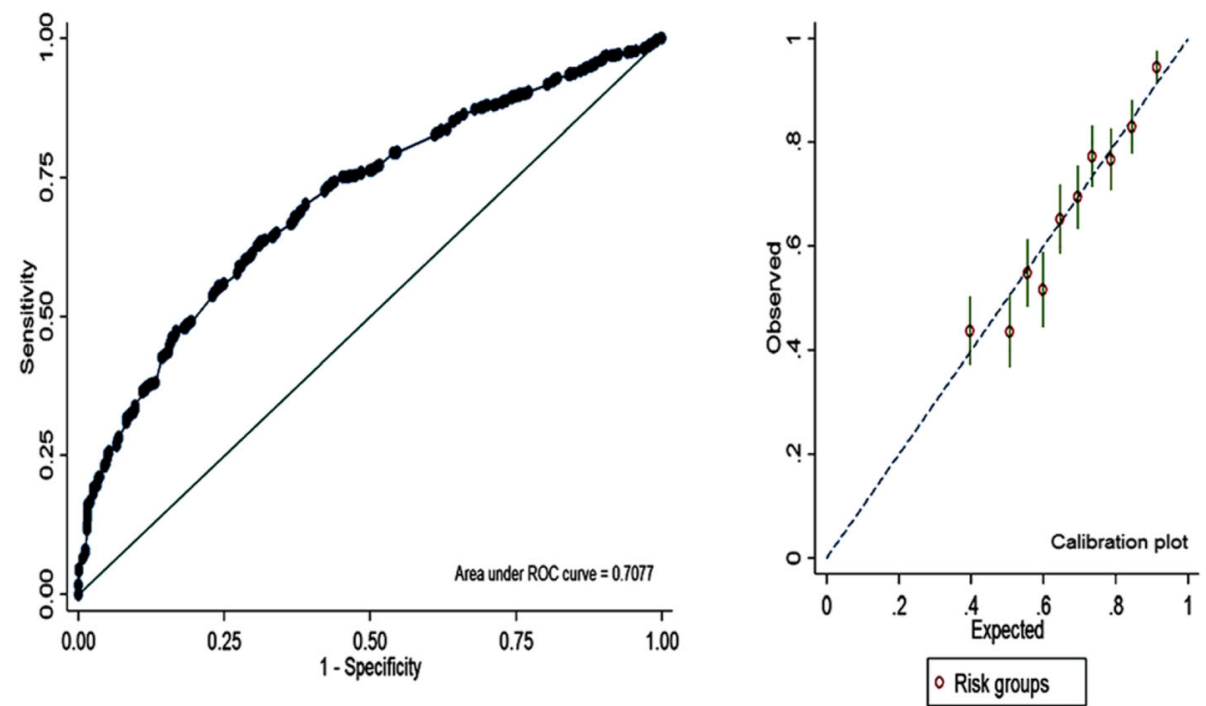

Fig. 2 Overall model discrimination and calibration plots for the delay in reporting fever $>2$ days using a community-based survey

days (Supplementary Fig. S3). The model calibration indices such as Brier scores, CITLs, and calibration slops also indicated the better fit for the delay $>2$ days. Calibration slopes for each fitted model were also indicating better prediction for delay $>2$ days (Supplementary Fig. S4).

Further, the results of univariable and multivariable logistic regression analyses for delay ( $>2$ days) in reporting with estimated unadjusted and adjusted odds ratio $(\mathrm{aOR})$ associated with various socio-demographic factors are presented in Table 3 using community-based survey. Location, religion, type of work, place of treatment, distance to hospital and type of hospital were significantly associated with the delay in reporting fever in the community-based survey. The interaction between age group 20-40 years and male gender (aOR $1.71 ; p=$ 0.010) was also associated with the higher odds for the delay in reporting for treatment of malarial fever. The fitted model for community-based survey showed $86.8 \%$ sensitivity, $33.5 \%$ specificity, and $68.6 \%$ overall classification. The Somer's D statistic was 0.415 , Brier score was 0.20 , CITL was -0.033 , expected/observed ratio was 1.01, and C-slope was 1.042. All of these measures were indicating good fit for delay $>2$ days in the communitybased survey. Overall discriminative ability and model calibration is presented in Fig. 2.

\section{Discussion}

Delay in treatment of malaria may cause severe illness and fatality. As reported, delay in the onset of treatment and the presence of complications on admission was found to be associated with mortality [13-15]. The factors associated with the delay in reporting for the treatment were evaluated in this study. Analysis of community-based survey of 1989 fever cases and hospital-based survey of 350 patients reported with fever indicates that the delay in seeking treatment of fever was mainly associated with severity of illness, age, and gender of patients. Additionally, the type of health facilities and its distance from the village/residence have also been identified as important factors [16].

To obtain the optimum cut off for delay to malaria fever case prediction, ROC curve approach has been used which is also defined as one of the appropriate methods to obtain optimum cut-point value in any scale by some other studies [10-12]. Optimum cut off for delay in reporting of fever cases that maximize (sensitivity + specificity) for higher prediction of malaria cases was found to be at $>2$ days, which also observed as optimum for malaria cases in another study [16].

Socio-demographic factors are found to be associated with delay in reporting for treatment such as age, gender, place of residence, monthly income, place of treatment, occupation, distance of health facility and type of facility. Delay in treatment-seeking was likely to be 1.5 times more among older age people (40+ years). It was also about two times more among those who engaged in agriculture occupation. Their negligence and prior commitment related to agriculture or farming work was the main reason of the delay as they were scared to lose their daily wages. In a study conducted in the Odisha state of India, the daily wage labours or small-scale farmers are not prompt to treatment-seeking [14], and such similar findings were also reported in other studies [17].

Delay in seeking treatment among rural people was likely to be two times higher as compared with urban, it was possibly due to distance and lack of proper facilities 
of health care services near their residence. In this study, most of the participants were resided in rural area and required to travel more than $5 \mathrm{~km}$ to get health facilities that could also delay seeking timely treatment, as previously reported by others [14, 16, 18-20].

Other symptoms with fever was also associated with delay and it has been described in many other studies. Mean days of the delay was slightly lower $(<4$ days $)$ in case of some symptoms such as joint pain, shivering and vomiting with fever for a community survey, otherwise, it was higher ( $>4$ days) with most of the symptoms with fever in community and hospital surveys. Such finding was also reported in hospital-based studies [21, 22].

Many studies reported that negligence by the patients was the primary reason for delay [14, 17, 22-26]. Similar findings are recorded in our study as $2-4$ days delay in reporting for treatment of fever with other symptoms related to malaria was observed in both surveys. Delay was also possibly due to the usage of traditional remedies and consultation to local unauthorised health service providers [3, 27]. The main strength of our study is using both datasets that complement each other to draw valid conclusions. However, there are some limitations of this study as we used hospital-based data to find optimal cut-off which may not have an actual representation of the general population. Another caveat to mention that the findings are based on retrospective data analysis. We also did not know about some other factors such as local medications, connectivity by road, and surface transport, etc. which may cause a delay in treatment as these information were not collected in the surveys.

\section{Conclusion}

Overall, the study presents valuable information related to the possible cause of delay which is useful for effective health policy and plan of a community-based intervention to eliminate malaria. Early treatment of febrile illness within 2 days of onset of fever to be implemented especially in the malaria-endemic areas. The consequences of self-medication and traditional beliefs may be discussed in the community and such practices need to be discouraged. As the distance of the health centre is a major cause of delay, the local transport or ambulance service may be provided by the government in rural areas for their convenience to commute. There is a clear need to have an integrated approach to provide minimum required health care services to the rural community in their village periphery and also to create awareness about early treatment of malaria through trained health workers. Elimination of malaria can be achieved, if health administration, private industries (tea, crude oil, and natural gas), and other local nongovernment organizations including local leaders of society make a joint effort for this endeavour.

\section{Supplementary information}

Supplementary information accompanies this paper at https://doi.org/10. 1186/s12889-020-08660-2.

Additional file 1 Figure S1. Spearman rank correlation between delay in reporting fever and duration of fever treatment in community-based survey $(n=84)$. Figure S2. Distribution of delay in reporting among fever cases in community- and hospital-based surveys. Figure S3. Classification plots for each cut-off value using hospital-based survey. Figure S4. Calibration plots for each cut-off value using hospital-based survey.

\section{Abbreviations}

ROC: Receiver Operating Characteristic; WHO: World Health Organization; NIMR: National Institute of Malaria Research; NVBDCP: National Vector Borne Disease Control Programme; RDT: Rapid Diagnostic Test; PSU: Primary Sampling Unit; AIC: Akaike information criterion; BIC: Bayesian information criterion; PPV: Positive Predictive Value; NPV: Negative Predictive Value; CITL: Calibration-In-The-Large; OR: Odds Ratio; Cl: Confidence Interval; INR: Indian Rupees; aOR: Adjusted Odds Ratio; SD: Standard Deviation; $\mathrm{km}$ : Kilometre

\section{Acknowledgements}

Authors would like to acknowledge the Indian Council of Medical Research, New Delhi for their financial support to conduct the survey. Furthermore, we would like to thank the scientific advisory committee for their valuable suggestions. We are also grateful to local health authorities, participating hospitals and study participants for accomplish the study.

\section{Authors' contributions}

HKC contributed to the conception, provided the data for this study, the data analysis and interpretation, and writing the manuscript. RCB contributed to the data analysis, interpretation results and writing the manuscript. PT contributed to prepare the data file (extracted the variables and coding) and analysis of data, and writing of the paper. All the authors read and approved the final manuscript.

\section{Funding}

There is no funding for this study.

\section{Availability of data and materials}

Data used and analysed during this study are available from the corresponding author only for research purpose which can be shared with the consent of the Indian Council of Medical Research.

\section{Ethics approval and consent to participate}

Ethical clearance for this study was not required as we have used the existing data collected in a previous project on health-seeking behaviour and reporting pattern to health center especially with fever symptoms funded by the Indian Council of Medical Research (Project Id No. 2003/ 01090). The project was also approved by the scientific advisory committee (SAC) constituted by ICMR. However, the written consent of selected individuals was taken before interviewing them during the survey. This is also reported in the previous publications of the project cited in the reference $[2,3]$.

Consent for publication

Not applicable.

Competing interests

The authors declare that they have no competing interests.

\section{Author details}

${ }^{1}$ ICMR-National Institute of Medical Statistics, Indian Council of Medical Research, Ansari Nagar, New Delhi 110 029, India. ${ }^{2}$ School of Primary, Community and Social Care, Keele University, Staffordshire ST5 5BG, UK. 
Received: 6 September 2019 Accepted: 6 April 2020

Published online: 28 April 2020

\section{References}

1. World Health Organization: Guidelines for the Treatment of Malaria (3rd ed). World Health Organization, Geneva; 2015. https://www.who.int/malaria/ publications/atoz/9789241549127/en/.

2. Chaturvedi HK, Bajpai RC, Pandey A. Risk of malaria among febrile patients: retrospective analysis of a hospital based study in an endemic area of Northeast India. Int Health. 2014;6(2):144-51.

3. Chaturvedi HK, Mahanta J, Pandey A. Treatment-seeking for febrile illness in north-East India: an epidemiological study in the malaria endemic zone. Malar J. 2009:8:301

4. Giao PT, de Vries PJ, Binh TQ, Nam NV, Kager PA. Early diagnosis and treatment of uncomplicated malaria and patterns of health seeking in Vietnam. Tropical Med Int Health. 2005;10(9):919-25.

5. Ogoina D. Fever, fever patterns and diseases called 'fever' - a review. J Infect Public Health. 2011;4:108-24.

6. Trampuz A, Jereb M, Muzlovic I, Prabhu RM. Clinical review: severe malaria. Crit Care. 2003:7(4):315-23.

7. National Institute of Malaria Research: Guidelines for Diagnosis and Treatment of Malaria in India (3rd ed). New Delhi, India: National Institute of Malaria Research; 2014. http://www.mrcindia.org/Diagnosis\%20of\%2 OMalaria\%20pdf/Guidelines\%202014.pdf.

8. Bhatia R, Rastogi RM, Ortega L. Malaria successes and challenges in Asia. J Vector Borne Dis. 2013:50(4):239-47.

9. Government of India, National Vector Borne Disease Control Programme: National vector borne disease control programme annual report 2014-15. New Delhi, India; 2016. https://mohfw.gov.in/sites/default/files/564 78563254566332556.pdf.

10. Blacksell SD, Lim C, Tanganuchitcharnchai A, et al.: Optimal cut-off and accuracy of an IgM enzyme-linked immunosorbent assay for diagnosis of acute scrub typhus in northern Thailand: an alternative reference method to the IgM immunofluorescence assay. J Clin Microbiol 2016, 54(6):1472-1478. https://doi:10.1128/JCM.02744-15.

11. Perkins NJ, Schisterman EF. The inconsistency of "optimal" cut-points using two ROC based criteria. Am J Epidemiol. 2006;163(7):670-5.

12. Unal I: Defining an Optimal Cut-Point Value in ROC Analysis: An Alternative Approach. Computational and Mathematical Methods in Medicine 2017 Article ID 3762651, 14 pages. https://doi:10.1155/2017/3762651.

13. Bhattacharya DV, Talukdar R. Transmission of malaria and its control in the north-eastern region of India. J Assoc Physicians India. 2003;51:1073-6.

14. Das A, Sundari Ravindran TK: Factors affecting treatment-seeking for febrile illness in a malaria endemic block in Boudh district, Orissa, India: policy implications for malaria control. Malaria J 2010, 9:377. https://doi:10.1186/ 1475-2875-9-377.

15. Deressa W: Treatment-seeking behavior for febrile illness in an area of seasonal malaria transmission in rural Ethiopia. Malar J 2007, 6:49. https:// doi.org/10.1186/1475-2875-6-49.

16. Kassile T, Lokina R, Mujinja P, Mmbando BP. Determinants of delay in care seeking among children under five with fever in Dodoma region, central Tanzania: a cross-sectional study. Malaria J 2014, 13:348. https://doi.org/10. 1186/ 1475-2875-13-348.

17. Sarkar J, Murhekar MV, Shah NK, van Hutin Y: Risk factors for malaria deaths in Jalpaiguri district, West Bengal, India: evidence for further action. Malaria J 2009, 8:133. https://doi:10.1186/1475-2875-8-133.

18. Vijayakumar KN, Gunasekaran K, Sahu SS, Jambulingam P. Knowledge attitude and practice on malaria: a study in a tribal belt of Orissa state India with reference to use of long lasting treated mosquito nets. Acta Trop. 2009;112(2):137-42.

19. Pawar AB, Bansal RK, Kumar M, Jain NC, Vaishnav KG. A rapid assessment of mosquito breeding, vector control measures and treatment seeking behaviour in selected slums of Surat, Gujarat, India, during post-flood period. J Vector Borne Dis. 2008:45:325-7.

20. Baume C, Helitzer D, Kachur SP. Patterns of care for childhood malaria in Zambia. Soc Sci Med. 2000:51:1491-503.

21. Matta S, Khokhar A, Sachdev TR. Assessment of knowledge about malaria among patients reported with fever: a hospital-based study. J Vector Borne Dis. 2004; $41: 27-31$

22. Mohanty S, Mishra SK, Pati SS, Pattnaik J, Das BS. Complications and mortality patterns due to plasmodium falciparum malaria in hospitalized adults and children, Rourkela, Orissa, India. Transact R Soc Trop Med Hyg. 2003:97:69-70

23. Reilley B, Abeyasinghe R, Pakianathar MV. Barriers to prompt and effective treatment of malaria in northern Sri Lanka. Tropical Med Int Health. 2002; 7(9):744-9.

24. Mishra SK, Mohanty S, Das BS. The influence of healthcare facilities on malarial mortality in and around Rourkela, India. Ann Trop Med Parasitol. 2002;96:835-7.

25. Munguti KJ. Community perceptions and treatment seeking for malaria in Baringo district, Kenya: implications for disease control. East Afr Med J. 1998; 75(12):687-91.

26. Guyatt HL, Snow RW. The management of fevers in Kenyan children and adults in an area of seasonal malaria transmission. Transact R Soc Trop Med Hyg. 2004;98:111-5.

27. Sonkong $K$, Chaiklieng S, Neave $P$, Suggaravetsiri P: Factors affecting delay in seeking treatment among malaria patients along Thailand-Myanmar border in Tak Province, Thailand. Malaria J 2015, 14:3. https://doi.org/10. 1186/1475-2875-14-3.

\section{Publisher's Note}

Springer Nature remains neutral with regard to jurisdictional claims in published maps and institutional affiliations.
Ready to submit your research? Choose BMC and benefit from:

- fast, convenient online submission

- thorough peer review by experienced researchers in your field

- rapid publication on acceptance

- support for research data, including large and complex data types

- gold Open Access which fosters wider collaboration and increased citations

- maximum visibility for your research: over $100 \mathrm{M}$ website views per year

At BMC, research is always in progress.

Learn more biomedcentral.com/submissions 